\title{
Learning-by-Doing and Knowledge Management in Financial Markets
}

Gordon L Clark. Smith School of Enterprise and the Environment, Oxford University, South Parks Rd., Oxford OX1 3QY, UK; Department of Banking and Finance, Monash University, Caulfield VIC 3145, Australia

\begin{abstract}
This article provides a model of the ways in which knowledge is defined and conceptualised in economic geography including reference to codified and tacit knowledge and how these concepts apply or do not apply to financial markets. This leads to a reinterpretation of learning-by-doing, and a call for a renewed focus on human behaviour especially as regards to the ways in which knowledge and understanding of financial markets intersect with management strategy and organisational design. Implications are drawn for economic geography about what appear to be two different and non-intersecting research programmes in the discipline - the knowledge economy and finance.
\end{abstract}

Keywords. Behaviour, finance, learning-by-doing, knowledge management

JEL Codes. D83, G14, L22

Disclosure. This article is the product of a shared research programme with colleagues at Stanford University on the governance and management of institutional investors and financial behaviour. It has benefited from the support of the Smith School at University of Oxford and the funding provided by its founders.

Acknowledgements. The author acknowledges the insights of Ashby Monk, Malan Rietveld and Peter Bruce Clark and collaboration with the late John C Marshall, Kendra Strauss, Janelle-Knox Hayes and Dariusz Wójcik. Marcel Metzner and Jennifer Sabourin provided assistance and editorial advice on the preparation of this article and editorial advise on the preparation of this paper and Harald Bathelt, Stefania Innocenti, Sarah McGill and two anonymous referees provided useful comments on this and previous drafts of the article. None of the above should be held responsible for any errors or omissions.

\section{Introduction}

The knowledge economy is an important theme in economic geography expressed, for example, in maps of patents (Feldman and Lendel 2010) and employment and occupations (Gabe and Abel 2012; Qian 2017). Just as important has been an interest in the processes whereby knowledge evolves in the light of experience (Gertler 2003). Amin and Cohendet $(2004,5-6)$ provide a review of the relevant management literature, the significance of path dependence in economics and geography, and the approach favoured by economic geographers which joins learning-by-doing with the "social dynamics of cultures and organizational cultures." When connected to clusters of innovation the knowledge 
economy is, fundamentally, characterized by geographical differentiation (Ibrahim et al. 2008; Broekel and Boschma 2012).

Running parallel to the research programme on the knowledge economy has been the research programme on the geography of finance (Clark and Wójcik 2007). This programme focuses, for example, upon financial centres, the geographical and temporal integration of global stock markets, and the political economy of finance in relation to nation-states and regions (Wójcik 2011, 2013). Having analysed the geographical origins of the 2007 global financial crisis (see Clark 2011; Engelen et al. 2011; Smith 2013), this field of study takes as given the problematic nature of financial markets. ${ }^{1}$ At the same time, given the significance of finance for economic development it is important to understand how and why financial markets work (or don't work) (Clark 2017).

This article begins with human behaviour referencing the literature spawned by Herbert Simon (1956) and the founders of the Carnegie school in economics who emphasized nonidealistic conceptions of human reasoning (see Levinthal and March 1993 on the limits of learning-by-doing). ${ }^{2}$ The Carnegie approach was then transformed by behavioural and cognitive scientists moving from deep knowledge of organisational performance to university test-subjects stripped 'clean' of context (undergraduate and graduate students). Much has been written about these developments and the research program spawned by Kahneman and Tversky (1979) amongst others (see Maskell and Malmberg 2007; Thaler and Sunstein 2008). They have done more than pick-apart the singular logic of microeconomics. There is a renewed focus upon the scope of human behaviour, including the robustness of learning-by-doing in different contexts (see Henrich et al. 2005).

\footnotetext{
1\% See also Stellinga and Mügge $(2017,397)$ arguing "(f)inancial markets traffic in futurology. When players in those markets price assets and liabilities, the evaluation routines are shot through with assumptions about the future" including "estimates of default probabilities, interest rate levels in the years to come, economic growth trajectories, foreign exchange movements, and so on. The possibility that firms' assessments are off the mark generates financial risk - and the crisis beginning in 2007 demonstrates just how badly things can go wrong".

\%. Financial organisations are often labelled and treated by governments as 'institutions'. Likewise, theorists also treat these organisations as institutions, being deemed fundamental to modern economies (Mayer and Vives 1995; Ben-David et al. 2016). In many cases, financial institutions are organisations in the sense that they are established systems of financial coordination and management (cf. Bathelt and Glückler 2011).
} 
By 'context' I mean the relevant or salient 'action spaces' of those who are the object of analysis (inside and outside of financial markets) (see Bordalo et al. 2012). Simon (1956) made a similar analytical move, suggesting that observed behaviour is the product of cognition and the environment in which people act. For contemporary economic geographers and many social scientists, the environment has come to be identified with biology, ecology and the Anthropocene - hence the use of the term 'context' in this article and elsewhere (Clark 2018a). For Simon, the relationship between cognition and context was to be found in a scissors metaphor wherein cognition was one blade and context the other. As implied, he treated each blade as equal in weight to the other. Observed behaviour was deemed produced through the interaction of both blades of scissors.

The scissors metaphor can be superficial if cognition is simply taken to mean how people process information against a priori interests and commitments and context is taken to mean the opportunity set (limited or otherwise) through which people realise those interests and commitments. This is a plausible way of representing the interaction between cognition and context, and is exploited in early sections of this article. However, standing behind contemporary cognitive science and behavioural psychology is a stronger claim: interests and commitments are neither transcendental nor are action spaces ephemeral (Lear 1986). Indeed, Fiedler and Juslin $(2006,8)$ suggest "the perceptual input from the external world even has priority over internal representations in memory, because the former determines the latter."

In the next section, a definition of knowledge is provided based upon the relevant literature and the particular conditions obtaining in financial markets. This is the basis for a typology of 'knowledge worlds' which links behaviour with different types of organisational strategies in financial markets. It is suggested that there is a premium on individual skills and expertise in financial markets-even so, learning-by-doing can be quite problematic in a world of heterogeneous beliefs and uncertainty (juxtaposing Arrow 1962 with Arrow 2014). It is argued that organisations have an important role in managing investment behaviour in relation to financial market structure and performance. But it is also argued that 
maintaining the coherence and integrity of financial institutions can be problematic. The article concludes with a brief assessment of the opportunities to be had in cultivating a rapprochement between the study of the knowledge economy and global financial markets.

Throughout, reference is made to the contributions by geographers, economists and financial theorists (separately and together). I draw upon research findings from various fields without reporting new findings related to (for example) the causes and consequences of global financial disequilibrium. The goal of the article is to re-assert the significance of an organisational perspective for understanding knowledge management in financial markets. In doing so, I interrogate Hayek's $(1945,519)$ observation that "knowledge of the circumstances of which we must make use never exists in concentrated or integrated form, but solely as the dispersed bits of incomplete and frequently contradictory knowledge which all the separate individuals possess."

\section{Market Form, Finance and Knowledge}

The global financial industry has grown exponentially over the past 50 years, there being approximately US\$5 trillion in play in FX markets and approximately US\$300 billion traded on stock markets every day (Wójcik per com). In terms of market structure, it is arguable that the industry is (1) an hierarchical pyramid where there are just a few truly global markets and many other markets that are increasingly 'local' towards the bottom of the spatial hierarchy and is (2) an inverse pyramid where just a few markets dominate the volume of assets managed in the industry. The integration of emerging markets and the periphery of the global economy with the global markets of London and New York and the increasingly important Asian markets of Tokyo, Hong Kong and Shanghai reflect the forces driving global financial integration since Bretton Woods (Wójcik 2013).

While many financial institutions and investment organisations are, in the first instance, dependent upon their 'home' markets for assets under management, the holding of assets in the industry is highly concentrated in the largest global players (see Clark 2016, 2018b on the spatial morphology of financial markets in the UK and Europe). For example, it is reputed that BlackRock alone manages US\$6 trillion dollars with clients spread around the 
world and with trading activities in more than 20 financial markets. Even so, smaller market players persist being part of a geographically and functionally-extensive system of financial intermediation. As indicated in the penultimate section of the article, persistence can be explained by specialisation just as it can be explained by alternative modes of knowledge management. Here, the building blocks underpinning the analytical framework are explained before applying them to organisational strategy and the spatial morphology of the industry.

\section{Knowledge and Information}

For all the research on the knowledge economy, precise definitions of knowledge are elusive. In some cases, knowledge is defined as "know-how" (see, for example, Baldwin 2016): that is, specific routines and practices informed by an understanding of how a process works under certain conditions (paraphrasing Amin and Cohendet 2004, 58-59). In this respect, knowledge is both substantive and procedural in that understanding how something works requires key concepts along with an appreciation of the conditions amenable to their use in particular circumstances. By implication, some economic processes are knowledge-intensive and others are not in the sense that any premium on knowledge has long been absorbed.

Formal definitions of knowledge emphasise understanding and comprehension, linking these concepts to proficiency in undertaking related tasks and functions. Dictionary definitions often compare knowledge against ignorance implying that knowledge is the mirror-image of ignorance. In a related vein, March $(1994,45)$ suggested "the greater the ignorance of decision-makers or those implementing the decisions, the greater the variability of the outcome distribution conditional on the choice." He suggested that "increases in knowledge have two principal effects on a performance distribution" thereafter associating knowledge with an increase in the "mean performance" and the "reliability" of a decision-maker. This shifts the focus from knowledge of economic processes to the knowledge of decision-makers, a helpful perspective given what follows. 
For some analysts, knowledge and information are much the same thing. While knowledge and information are related, it is arguable that knowledge determines the salience or otherwise of information regarding the intended and measured performance of a decisionmaker and/or economic process. Specifically, "information can be defined as the flow of data from the environment. Knowledge can be defined as information (received, purchased, and/or found) processed against a template or model of the world" (Clark 2014, 301). Likewise, Howells $(2012,1003)$ contended “(k)nowledge can be defined as a dynamic framework from which information can be stored, processed and understood." In some situations, information comes at a price. In other situations, information comes easily to hand, being collected, packaged, and distributed every minute of every day. ${ }^{3}$

The virtue of any model of the world is to be found in its utility, performance, and the valuefor-money embedded in working from one model as opposed to a competing model. Whereas logicians tend to favour parsimony and simplicity when assessing the use and production of knowledge in decision-making, there is inevitably a trade-off between the clarity of a model and its applicability to the world observed and encountered (Gilboa et al 2014). Some models may well represent knowledge of the world which is stable and coherent albeit, as a consequence, rather abstract in terms of its application to specific conditions. Other models may represent knowledge that is incomplete in the sense that it is contingent on certain conditions and/or the boundaries between domains that are subject to unanticipated change (as obtains in financial markets)

\section{Analytical Framework}

Knowledge comes in various forms, in some cases being presented in formal terms along with an explicit statement of its object, domain, and the conditions regarding its applicability. In other circumstances, it may be difficult to formulate an explicit statement

\footnotetext{
$3 \%$. The provision of financial information has become highly automated, provided by third parties with extraordinary reach over time and space at a price. Nonetheless, the quality of information remains an issue and can be a source of comparative advantage if financial institutions develop bespoke tools to process information in ways that add insight as to the integrity of market systems (Clark and Monk 2017).
} 
recognising that its articulation could be contingent on conditions and factors either not fully understood and/or subject to uncertainty. Indeed, in many circumstances, financial processes are likely to be, by their very nature, unstable. In these circumstances, knowledge is typically embedded in practices and routines whose utility is judged against their immediate use-value. Furthermore, financial traders may come to believe that keeping knowledge informal (in this sense) is in their best interests. Simplifying the discussion, Figure 1 provides a $2 \times 2$ matrix wherein the scope of knowledge is either complete or incomplete and where its articulation is either formal or informal. Four types of knowledge are identified. ${ }^{4}$

One type of knowledge $(A)$ is complete in terms of being able to articulate its scope and is represented in a formal manner that can be communicated to others. Indeed, it could be transferred to others without any loss of effectiveness: it looks just like a rulebook or manual which has been tried and tested so as to ensure that it is the best possible guide to decision-making. ${ }^{5}$ By contrast, another type of knowledge (D) is incomplete in that it is not possible to be definitive about its scope recognising that there are forces at work (recognised or not) that could disrupt its coherence. As a consequence, there may be little value in a formal representation of its logic and applicability. Those with a vested interest in operating in this type of domain may well use heuristics that are conditional upon an intimate knowledge of the interaction between the logic underpinning the model and the immediate environment (Gigerenzer et al. 1999).

\footnotetext{
4 . This matrix is a stylised account of a complex process that is not always as coherent as implied by the figure's four mutually exclusive cells. See Arjaliès et al. (2017) for a similar attempt to bridge case-specific knowledge of financial institutions and markets with an analytical framework. Type A and Type D situations are also found in a similar matrix provided by Streeck and Thelen (2005, 8-9). They referred to Type A situations as those where adaptive change serves to protect continuity utilising devices such as rule-books and related norms whereas Type D situations are those where disruption can precipitate the collapse of decisionmaking and related organisations. Stefania Innocenti (per com).
}

5 . Rule-books have evolved from informal statements of operating procedure to formal statements of bestpractice policies and procedures which are normally asset class-specific (bonds, equities, infrastructure etc). In some cases, rule-books together represent the investment philosophy of an organisation. Rule-books provide portfolio managers with discretion-within-limits given company-wide oversight of the risks associated with investment. Rule-books can also stand in place of real-time data on risk exposure in circumstances where the collection and dissemination of risk-data is expensive and subject to short-term noise (Clark and Monk 2017). 
[Insert Figure 1 About Here]

In financial markets, Type A situations are found in certain asset classes like government bonds and traded equities wherein the pricing and exchange of these securities discount discretion and favour automated trading systems that rely upon rulebooks. Note, however, whether these rulebooks work depends upon the sophistication of market players, the integrity and availability of market-relevant information, and the mutual acceptance of these rulebooks amongst market players (MacKenzie 2006). By contrast, Type D situations are often found in emerging markets that are dominated by heterogeneous expectations, information that is unreliable and/or suffused with hidden interests, and where there is very little in the way of accepted norms and conventions underpinning the relationships between market players (Clark 2014).

Type B situations exist where knowledge of a financial process is incomplete but where there is value to be had in its formal articulation, especially as regards to its boundary conditions and scope of applicability. In this sense, to the extent that there is value in completing a formal model of a particular type of process then Type B situations could become Type A situations over time. What of Type $C$ situations? Financial agents may well have a very good understanding of the nature and scope of a market process but, because of the robustness of market relationships and the integrity of norms and conventions, need not go a step further and formalise that knowledge in a rulebook. Here, the lack of a rulebook need not be a barrier to entry into a market - the wide-acceptance of norms and conventions like the Black-Scholes theorem could be sufficient to encourage outsiders to enter local markets (Ho and Lee 2004).

\section{Behaviour and Organisation}

In some branches of social science, notably economics and management studies, a model of the world is a formal statement about the motive forces behind behaviour, the conditions 
under which these forces operate, and the likely results or outcomes obtaining in such environments (Gilboa et al 2014). In these circumstances, the formulation of a model of the (relevant) world relies upon the identification of the salient economic and social forces at work as well as identification of the boundary conditions that determine the applicability or domain of such a model. This section takes the analytical framework introduced above and complicates the picture in two ways. First, it is noted that knowledge management in financial institutions can be problematic in that it involves the management of people (employees). Second, models of financial markets are problematic both in terms of their stability and in terms of their applicability.

Large financial institutions, seeking to manage the investment process such that they control employees' risk-taking and return-seeking behaviour, aim to control, as much as possible, Type D situations while favouring Type A situations. That is, managers' claim oversight of their employees' positions as well as their investment strategies against rulebooks that are asset-specific (e.g. trading in global equities, bonds etc.) and which allow for an assessment of the likely consequences of those strategies against the sponsoring institution's overall targets. ${ }^{6}$ In these situations it is often difficult for portfolio managers to make a premium over and above the costs of trading given that other portfolio managers trading in the same domain and employed by institutions that share similar rulebooks for investment decision-making tend to converge on the same strategies (Ben-David et al. 2016). In these situations, adding value over and above industry benchmarks is only possible if portfolio managers have better and/or faster access to market information than their peers (Shleifer 2000).

By contrast, Type D situations hold-out the promise of much higher returns (and much higher losses) against industry norms. In these cases, there is a premium on understanding the boundary conditions determining the success or otherwise of competing investment

6 . Whereas the media and commentators on the culture of the financial services industry tend to focus upon the behaviour of individual traders, investment strategy is almost always framed at the intersection of the interests of clients, financial organisations and their employees (Clark 2018b). 
strategies; these strategies are typically neither codified nor easily accessed by senior managers seeking to understand employees' risk-taking and return-seeking behaviour. This is, of course, widely known both within institutions and between institutions in the global financial services industry. Those institutions that have effective but bespoke oversight procedures that can, at once, take advantage of the tacit knowledge of their portfolio managers while providing controls on their risk exposures in a manner consistent with the sponsoring institutions' goals and objectives (e.g. solvency) are likely to be more successful than those institutions that are ineffective on these counts.

Much of the literature on the knowledge economy is about the transfer of knowledge within and between organisations and the interplay between organisations and social relationships. See, for example, Agrawal et al. $(2006,572)$ who focused upon the "particular role of social relationships in mediating knowledge flows" and the extent to which "the presence of a social relationship reduces the importance of spatial proximity in mediating knowledge flows". In this context, the lack of accepted investment protocols which allow for effective oversight makes the management challenge quite problematic. Other cases are less problematic. For example, in Type $C$ situations senior managers could have a good understanding of how an asset class works and, as a consequence, rely upon their asset managers' tacit knowledge to realise above-average returns subject to honouring the obligation of transparency.

Underpinning this model of knowledge management are two key assumptions. It is assumed that managers of financial institutions and their employees are rewarded for, respectively, knowing what portfolio managers do and how they do it and knowing how their part of market works and how to realise investment returns that are at least equal to if not superior to other similarly-placed portfolio managers. Given that portfolio managers are closer to the market than their managers, and given the incentives on portfolio managers to take advantage of information not readily accessible to either their competitors or their senior managers, it is also assumed that portfolio managers are likely to operate at the margin of market expectations. Senior managers are likely to use formal 
models of the market as a means of imposing constraints on portfolio managers thereby holding them to account for taking risks inconsistent with expectations.

In this respect, we need an explanation of how portfolio managers make and use knowledge under conditions of risk and uncertainty. A widely accepted approach found in behavioural psychology and cognitive science relies upon an equivalence made between knowledge and models of the world wherein the latter is deemed to represent the knowledge of a certain domain expressed in terms of propositions, conditionals, and boundary conditions (Hilton 2003). This could be informal. Johnson-Laird $(1983,10-11)$ suggested that many people rely upon their intuition and incomplete models of the world that are "merely imitations of reality". By contrast, more sophisticated players, recognising that these models of the world are subject to systematic errors, may well invest time and effort into "constructing working models" of the world. This distinction, expressed in slightly different terms, is widely noted in cognitive science; see Kahneman (2011) and Mercier and Sperber (2017) amongst others.

Johnson-Laird's approach was based on three fundamental assumptions. In the first instance, it was assumed that however incomplete a person's knowledge and understanding of their domain, they begin from this point when encountering new information or a decision that must be taken that goes beyond convention. In the second instance, it was assumed that most people, most of the time economise on effort such that they tend to exclude the unfamiliar in favour of the familiar thereby narrowing the range of possibilities and facilitating convergence upon an immediate solution. In the third instance, it was assumed that immediate (selected) experience is just as important as established rules-ofthumb (heuristics). Put slightly differently, first-order models of the world are not so stable or so coherent that they can be used to effectively predict (as opposed to infer) the future.

By contrast, a great deal of effort is required to construct a working model of the world, one that relies upon first principles, can rank-order the conditions that apply to those principles, and can provide boundaries as to the relevant domain of such a model. Working models are 
well-represented in the global financial services industry. They come in two different forms. In the first instance, these models can be found in textbooks, manuals, and industry accreditation bodies that, in effect, licence investment professionals to operate in the industry (see Ho and Lee 2004). In the second instance they can be found in operating models of investment management that are distinctive to an individual or group, their firms, and their particular corners of the market. Often associated with hedge funds and active investment, working models are, more often than not, conceived in opposition to first-order models of the financial world.

It is arguable that first-order models of the world are more consistent with tacit knowledge and are associated with incomplete and informal conceptions of knowledge management (Type D situations) than they are associated with codified conceptions of knowledge management (Type A situations). Even so, whatever the costs associated with intuition compared to working models of the world, in certain circumstances the former may produce a rate of return far superior to the latter just as it may produce, in other circumstances, a rate of return far below that produced by a working model of financial markets. Bradley et al. (2017) show that working models combined with domain-specific experience can make a significant difference to the forecast accuracy of industry analysts who, otherwise, share the same models of industry structure, the same information on corporate performance, and the same systems of reward.

\section{Knowledge and Talent}

While all industries face significant challenges in converting knowledge into competitive advantage (Gertler 2001), it was suggested above that the investment management industry faces a number of domain-specific challenges to realising the benefits of learningby-doing. There are various ways of dealing with this issue. One strategy has been to rely upon talented 'star managers' that can be hired and fired on the basis of their period-toperiod relative performance. This is a common practice in the financial services industry; the market for talent stands in place of social relationships and the management of knowledge within and between organisations (compare Agrawal et al. 2006, 572). 
There is a large literature on talent, with seminal papers by Rosen $(1981,1986)$ and recent work by Florida (2002) and others linking talent and identity with spatial differentiation (see Breschi and Lissoni 2009). Elsewhere, talent in the financial services industry is defined in terms of individuals' skill and expertise: skill is deemed to refer to domain-specific technical capabilities such as pattern recognition and the representation of financial data for investment strategy while expertise refers to individuals' knowledge and understanding of how financial markets work including how markets respond or could respond to endogenous and exogenous shocks (Clark 2016, 171). Talented individuals in the global financial services industry are able to outperform their peers in circumstances where the widespread use of conventional rulebooks may convert a run on the market into a fullyfledged financial crisis (Ben-David et al. 2016).

There are various ways of representing talent in financial markets, distinguishing between traders that respond to market 'noise' as opposed to market 'signals' (Scheinkman 2014). These accounts can appear simplistic, being denuded of the incentives driving behaviour in certain kinds of markets. Nonetheless, simplicity often hides a deep understanding of how people behave in financial markets (see Grossman 2014). A more nuanced approach has been suggested by Akerlof and Shiller (2009) linking traders' behavioural predispositions with social norms and conventions. ${ }^{7}$ Other studies take an anthropological and/or geographical approach, reporting on how financial organisations work and the status of star traders in those organisations - witness Lewis (1989) on Salomon Brothers. Yet other studies link site-specific fieldwork with theoretical analysis, producing an image of the world which situates individuals in context (see Riles 2011).

7/. Akerlof and Shiller $(2010,1)$ begin their account with reference to John Maynard Keynes' "animal spirits" what they define as the "thought patterns that animate people's ideas and feeling". But they do more than this; they move swiftly from subjectivity to patterns of behaviour that express shared values like fairness and antisocial behaviour like the exploitation of those market participants that are ill-equipped to 'play the game'. 
Here, insights gleaned from research on institutional investors and the global financial services industry are used to provide, in a summary fashion, a glimpse of how talent is conceived and expressed in the industry (see Clark and Monk 2017). Wagner $(2002,57)$ runs through a similar set of characteristics associated with expert judgement albeit domain-neutral. Assuming the existence of heterogeneous behaviour in financial markets, assuming that these markets are characterised by risk and uncertainty such that hidden from view are some of the most important drivers of market dynamics, and assuming that traders are rewarded for actions taken in anticipation of market performance then knowledge and talent combine in the following ways.

- Successful investment managers are able to look through the data representing past and present market performance to underlying conditions either not directly represented in the data or whose presence in the data is shrouded by market sentiment that emphasises other issues and other explanations. Eschewing the status quo, talented investment managers use their working models of financial markets to search for underlying patterns and processes even if discontinuous and unstable.

- Successful investment managers are able to reproduce past success by, in part, juxtaposing the unexceptional with the exceptional. That is, they take current and past performance along with market sentiment and use counterfactuals to help identify the risk map underpinning current strategies as opposed to the alternatives. So, for example, notwithstanding the euphoria associated with the 2007 global financial market bubble, a number of successful managers at the time used experience from the 1930s to build best-case and worst-case scenarios. Talented investment managers are wary of myopia (Clark 2011).

- Successful investment managers frame their strategies in the light of their knowledge and understanding of market dynamics including the mix between momentum and fundamentals, and the likely behaviour of other players in the 
market. Where uncertainty is an ever present threat to realising the best laid plans, the response of other market players to unexpected events is as important as the events themselves. As Arrow suggested $(2014,84)$, in a world of heterogeneous beliefs others are likely to respond to the same information in different ways just as they are likely to seek information which is deemed, by talented investment managers, as irrelevant to the main game.

- Successful investment managers eschew simplicity for complexity simultaneously assessing the plausibility of commonplace rules for investment while picking apart those rules in relation to observed and possible futures. One of the identified shortcomings of the investment management industry is the fact that portfolio managers with asset-class specific investment strategies may be unable to deal with financial markets when risk measures are driven by the interaction between asset classes around the world rather than within asset classes and within specific financial markets. Haldane and May (2011) have identified this version of complexity along with related problems of effective policy-making as one of the most important factors that drove global financial markets into the 2007 crisis.

- Successful investment managers are better able to recognise unusual or so-called exceptional events than neophytes or rule-bound investors who tend to discount these situations in favour of 'normal' market forces. Discounting occurs because investment processes tend to become routine when markets settle, information management systems are rarely set-up to focus upon the exceptional as opposed to the normal, and most people find it difficult to integrate rare events into decisionmaking (see Kahneman and Tversky 1979; March et al. 1991).

More specifically, talented investment managers use their knowledge and understanding of financial markets to (1) interrogate the drivers of market performance, (2) avoid wherever possible the presumptions favouring myopia, (3) frame investment strategies that take into account the behaviour of other market players when encountering unexpected events, (4) 
look for situations where simple rules are confounded by the complex interplay between otherwise independent drivers of market performance and behaviour, and (5) appreciate and interrogate exceptions to expectations thereby discounting rule-led behaviour in favour of a holistic perspective. This is not a full list of how talent is expressed in financial markets or, for that matter, how talented individuals use their expertise to circumvent the costs associated with behavioural biases.

\section{Heterogeneity of Market Behaviour}

Talented investment professionals process market information including information about others' actual and expected behaviour, better than their competitors. Their standing in the market, and in their own organisations, is all about processing information in ways that sustain long-term returns against the relevant benchmarks (Shleifer 1985). Talented professionals are also more flexible when it comes to their commitment to conventional models of market performance and their own versions of those models: their knowledge and understanding of market performance is malleable rather than fixed in time and space.

These insights are often expressed in terms of Bayesian reasoning wherein expectations are "the by-products of stored causal relationships" which "represent and respond to external or spontaneous changes" (Pearl 2000, 22). Bayes' rule provides a means of representing existing knowledge about how a process works along with the conditional probabilities associated with expectations about the future. It also provides a rule for updating beliefs in response to new information, thereby integrating the past, present, and expected future into decision-making. Arguably, the most successful investors either use Bayes' rule explicitly or use it as an intuitive prompt when assessing options in relation to the future.

Where knowledge of market dynamics can be expressed in a set of causal relationships along with well-defined expectations about future states, it is arguable that Bayesian investors are more than likely to outperform naive investors. That is, to the extent to which a Bayesian framework provides a means of efficiently processing new information about 
market movements and, thereby, providing a means of framing conditional expectations of the future, Bayesian investors are likely to be quicker and less prone to error than naive investors. However, there are limits to Bayesian reasoning in financial markets - the points made immediately above as regards the ability of talented investment managers to rework their knowledge and understanding of market performance suggests that these types of market players also know when to abandon Bayes' rule.

This brief discussion of the status and relevance of Bayesian reasoning suggests that there are at least three different types of players in financial markets. There are those that are simply momentum players, responding to market information in ways that favour the most recent events disregarding underlying causal relationships and the established decision frameworks (neophytes). There are those that have well-developed models of market performance along with a set of rules to guide decision-making. These types of market players are rule-observant to a fault (rule-bound). There are then talented market players that continuously build, adapt, and even abandon models of the market using knowledge and information to take advantage of other market players (Arrow 2014).

Why are neophytes and rule-bound players myopic (Clark 2011)? Why can't they approximate the sophistication of the most talented investors via learning-by-doing? There are three possible explanations. One explanation is that neophytes simply lack the capabilities and resources necessary to be competitive in financial markets given the building blocks driving the production of investment performance (Clark and Monk 2017). This is, quite obviously, important given the problems facing market players (individuals and institutions) that are under-resourced. A second explanation would have it that the industry is dominated by norms and conventions such that knowledge and understanding of how markets work are first and foremost framed with reference to current practice rather than the evolving world of financial markets (MacKenzie 2006). That is, the apparent and recurrent convergence of many market players on rulebooks for investment decisionmaking is, in the aggregate, self-defeating. 
While important, there is a more problematic explanation - one based in behavioural psychology and cognitive science. To the extent that investment decision-making relies upon the effective processing of information from the market (specifically) and the wider economy (more generally) against some informed benchmark then learning-by-doing can be confounded by systematic behavioural traits that, more often than not, discount both the effectiveness of information collection and the application of selected information to the decision-making process (Aragones et al. 2005).

In this vein, Fiedler and Juslin $(2006,8)$ noted " $(\mathrm{t})$ he information provided by the social and physical environment can be highly selective as a function of spatial and temporal constraints, social distance, control restrictions, or variable density of stimulus events." Fiedler and Juslin go on to suggest that people "are exposed to denser information about ingroups than out-groups of their own culture than to other, exotic cultures." Individuals are inevitably 'partial' in terms of the nature and scope of information they select to inform decision-making. If left to themselves, they either lack the requisite knowledge, or they lack the resources required, or they lack the analytical and conceptual sophistication needed to realise the benefits from learning-by-doing.

Most importantly, behavioural theorists show that selection is not (just) an issue of circumstance but is a human trait in that people always select from the available information (Kahneman 2011). This is most obvious in global financial markets and at the intersection between individual behaviour and investment management. Neophytes and rule-based market players are often unaware of their selection biases unless their employers have prompts designed to hold them accountable. Note, however, this implies that organisations are able to rise-above and compensate for individual shortcomings. Some are able to do so, combining incentives and sanctions to reinforce the authority of senior managers over the actions and expectations of investment managers (Prendergast 1999). However, this may result in Type A situation where individual discretion is so constrained by rulebooks that opportunism is impossible except by subterfuge. 


\section{Solutions to Knowledge Management}

In any event, it is arguable that financial markets are epitomised by Type $C$ domains. This suggests that market performance is especially dependent upon adaptation and learningby-doing such that there is a premium on adaptation to unexpected events (responding rather than holding fast) notwithstanding the immediate benefits of learning-by-doing (being more effective) within certain parts or segments of the investment management industry (Lo 2012). The tension between adaptation and learning-by-doing can be explained in three ways.

In the first instance, Weitzman (2007) contended that the volatility of financial markets is more pronounced than is volatility in the real economy, indicating that these markets are not only dominated by flux and flow; the realisation of value is also dependent upon managing in a deliberate manner risk and uncertainty. That is, whereas risk and uncertainty could be seen as imposing costs on commodity producing industries, the life-blood of financial markets is their capacity to allocate the costs and benefits of financial risk and uncertainty to those able and willing to realise value (Mayer and Vives 1995).

As is the case in many sectors, risk can be modelled and managed within bounds. In finance, however, uncertainty is the product of unrecognised and unobserved parameters shifting in ways that are difficult to anticipate in a systematic manner. In these conditions, different models of the market are different ways of dealing with risk and uncertainty leading to the coexistence of different kinds of trading strategies and behaviour. This second point is often represented by the coexistence of heterogeneous expectations and, in models of financial markets, two different types of traders - those that trade on noise and those that trade on fundamentals (Scheinkman 2014). The existence of heterogeneous expectations means that "once I form my beliefs, you form yours; my beliefs will alter to reflect behaviour induced by your beliefs, and so on" (Arrow 2014, 83). By implication, market convergence on a stable reference point is unlikely except by happenstance. 
Learning-by-doing is confounded by a third issue. Imitation of success is recognised as one of the hallmarks of learning-by-doing (Pinch et al 2003); competitors adopt the practices and routines of others that are deemed worthy of emulation. In financial markets, however, the trick is to use skill and expertise in ways that stand apart from the mainstream in favour of strategies that take advantage of the mainstream (Glode et al. 2012). Given the premium on accumulating funds under management, successful traders tout their skill rather than luck (where trading strategies worked because of the confluence of positive, reinforcing factors), happenstance (being in the right place at the right time) or inside knowledge (subverting the flow of information to the market). Stories abound in the industry about the success of innovative trading strategies notwithstanding the significant challenges involved in replicating success.

These issues can be managed in ways that facilitate adaptation and learning-by-doing. Financial institutions have developed knowledge management systems so as to deal with many of the challenges involved in sustaining long-term success (Monk et al. 2017). Here, four stylised models of management are presented to illustrate the nature and scope of knowledge management systems in the investment management industry. Each one, in its own way, seeks to integrate learning-by-doing with adaptation to the ever-changing realities facing financial institutions in global markets. The first model is the dominant model in the industry, eschewing organisational learning in favour of hiring-and-firing from the market on the basis of relative performance. Models 2, 3 and 4 are related in that each seeks to cultivate organisational cultures of adaptation and learning in quite different ways matching Cohendet et al.'s $(2014,931)$ observation that epistemic communities seek "a shared understanding of their work".

Model 1: Divide and conquer. Given market risk and uncertainty and the difficulties involved in predicting future performance in circumstances where the reasons for current success are not easily understood, financial institutions often hire and fire on the basis of investment managers' previous measured performance (Hilton 2003). These types of institutions use recognised market-based incentives that reward adaptation and the 
valorisation of learning-by-doing. It is a mode of management that shares success between financial traders and their sponsors, but imposes the costs of poor performance on loosing traders and society (Prendergast 2002). These organisations often select successful traders from other competing organisations, treating global financial markets like London and New York as a common talent pool in a never-ending tournament of talent (Rosen 1986).

This organisation is the default model in the global investment management industry. It is also a type of organisation that can be established in major markets around the world where the dominant ethos of the home base becomes the standard operating model for units or branches of the same organisation in other markets and in other national jurisdictions. The replication of this type of organisation across markets is owed to shared systems of incentives and sanctions as well as overlapping and intersecting asset specific mandates and management teams. This kind of organisation also attracts certain types of employees whose interests are met by this type of organisational form (whatever the country or market) while it repels those who don't believe that their best interests are served by living and working in a divide and conquer regime. See van Staveren (2014) on the 'Lehman sisters hypothesis' as it pertains to the organisational culture of major investment houses up to and through the global financial crisis.

Model 2: Internal cultures of criticism and transparency. By contrast, there is another kind of organisation that promotes critical reflection on performance, debate over investment strategies conceived and implemented, and transparency as to what succeeded and failed across the organisation over the short to medium terms. In this type of organisation, industry norms and conventions such as those embedded in the standard rulebooks that dominate investment practice are the object of scrutiny and debate. These can be 'fierce' cultures of criticism, and can result in debasement and humiliation, driving-out those who are unable or unwilling to contribute to the learning culture. Cultures of criticism can also be constructive in that investment managers are required to explain and justify their actions thereby encouraging second-order reflection and evidence-based behaviour in 
circumstances where the driving forces behind market movements can barely be glimpsed (Mercier and Sperder 2017).

Norms such as self-respect, collegiality, and trust in others in the face of continuous comment and debate are integral to the success of these types of organisations (Dalio 2017). More often than not these types of organisations are setup in opposition to the dominant culture of the global investment management industry as found in national financial centres and London and New York. However, it has been observed that this type of organisation may flourish best in situations where individualism is a core element of national culture as opposed to situations where individualism is always dampened by expectations of compromise and commitment to others. It is notable that attempts to transplant this kind of organisation to Asian markets and northern European markets have been confounded by an unwillingness to play the game.

Model 3: Shared responsibility and accountability. In another type of organisation, wary of the adverse consequences of open debate about success and failure, the dominant culture is one of shared responsibility and accountability for the performance of the organisation. Here, the organisation is conceived in terms of the sum of its parts and the role that each plays in realising overall investment returns. Shared responsibility requires portfolio managers to mobilise their teams in ways that reinforce collective not just individual success. In these organisations, rule-books go beyond specific asset classes to encompass the whole organisation.

As such, this model of knowledge management is deeply social and is sustained by a longerterm perspective compared to the divide and conquer and criticism models of investment management. Here, compensation systems reinforce a sense in which portfolio managers responsible for certain parts of the investment process are rewarded for their own performance and share in the success (and failure) of the whole organisation. Inevitably, the organisation's most successful managers do not earn what they might earn if they were to switch to firms reliant upon models 1 and 2. As such, it may pay such organisations and 
their sponsors to be at some distance from global financial centres, reinforcing 'local' norms and conventions over 'global' expectations of compensation and success (see Dixon and Monk's 2014 frontier hypothesis).

Model 4: Goal-oriented investment management. Yet another type of organisation has developed in the face of the costs and benefits of each of the previous three models of investment management. Whereas each of these models is, in their own way, a formula for success wherein investment professionals are separately and/or collectively rewarded for the market performance of their organisation, some financial institutions have sought to shift measures of performance towards common objectives such as the welfare of clients, fostering long-term relationships with clients and related investment organisations, and the integrity of the organisation. This type of organisation comes in a variety of forms. For example, it could be created as a partnership wherein 'employees' are, or become after a certain time, co-owners of the enterprise. This organisational strategy is designed to discount the opportunism associated with the never-ending tournament for talent apparent in the leading financial centres of the world.

In other cases, this type of organisation is deliberately described in terms of its social objectives. As a consequence, the compensation premium claimed by investment managers in terms of their ability to adapt to market realities and reap the benefits of learning-bydoing is supplanted by an organisational claim as regards their commitment to long-term social welfare. These types of organisations are, in a sense, conceived in opposition to the ruling ethos of the industry (Model 1 ) but are only possible when (a) compensation systems lock in otherwise in-demand investment professionals and (b) long term performance is valued over short term performance by sponsors, managers and clients alike. These types of organisations can be found in London and New York but derive much of their return premiums through the recruitment and retention of talent available in these centres.

Each of these models of management is based upon an assumption that the financial world need not default to Model 1 if it can be shown that there is value to be had in a different 
organisational form with respect to adapting to risk and uncertainty and realising the benefits of learning-by-doing. Indeed, it is assumed (as economic geographers assume) that organisational integrity can be sustained by organisational formations and relationships that stand against conventional market incentives (see Poon et al. 2017). In this vein, and specific to the finance industry, it has been observed that these types of strategies are best conceived and implemented where there is a geographical separation between financial market centres and the sites of the production of investment management services (see Dixon and Monk 2014; Urban 2017).

To make a success of these models contra Model 1 would seem to require the following. First, to the extent that the culture of an organisation is integral to its long-term success, ways must be found to insulate it from individual compensation and reward systems that are market-reliant. Second, the integrity of each model also depends upon maintaining the boundaries of the organisation against the default model and against competing models that similarly seek to discount the influence of the market for talent. This is very challenging, given the pervasive influence of market intermediation (Arjaliès et al. 2017). Third, these models require both a defensive posture and an affirmative argument about the purpose of the organisation both in terms of its shared objectives and in terms of its capacity to adapt to risk and uncertainty when creating value.

At the limit, these organisational-cum-geographical solutions to knowledge management may become self-referencing games of influence (until they fail). The culture of an organisation may become so 'authoritative' that which counts as knowledge of the market and that which counts as relevant information in relation to the house-rules of investment management are pre-determined by internal norms and conventions. In these ways, an organisation can fail precisely because its culture becomes a self-referencing filter on what is market 'noise' and signal'. Furthermore, an organisational culture can implode in the face of the market for talent if investment managers come to believe that (internal) success is a zero-sum game. Cultures of criticism that require the justification of past decisions tend to encourage collective responsibility for investment performance; but cultures of criticism can 
also produce norm-convergence behaviour so as to avoid being isolated in a downturn notwithstanding the (transitory) advantages of past success.

\section{Implications and Conclusions}

I have argued that the knowledge economy can inform research on how and why financial markets work the way they work. In doing so, my approach was not particularly unusual in that I have conceptualised the knowledge management process as depending upon the interaction between individual behaviour and management over space and time (see Howells 2012). Likewise, my argument can be allied with arguments found in economic geography and elsewhere to the effect that "human knowledgeability is inseparable from social practice" (Grabher and Ibert 2013, 99).

Whereas the article draws upon the nature and scope of the knowledge economy in economic geography, throughout I sought to interrogate the theoretical building blocks underpinning the research programme by using these same building blocks to explain how and why the global financial services industry is organised as it is in terms of the valorisation of knowledge in global financial markets. Here, I was concerned with how financial institutions manage knowledge, how they adapt to risk and uncertainty and how they realise the value (or not) of learning-by-doing by their own employees in financial markets. In this respect, it is argued that knowledge management for the purpose of adaptation to risk and uncertainty is embedded in systems of learning that are market-based and often reliant upon specific kinds of organisations and geographies (see Clark and Monk 2017).

Whereas I focused on learning-by-doing, honouring Arrow (1962), I also identified the limits of learning-by-doing in financial markets. In large part, these limits are organisational as well as individual in that adaptation in the industry involves both. I also stressed the distinctive attributes of global financial markets and the ways in which risk and uncertainty confound knowledge management and learning-by-doing over time and space. Here, Arrow's more recent contributions on the knowledge economy (Arrow 2016) and the 
problematic nature of expectations in financial markets (Arrow 2014) have considerable bite. Most importantly, it was suggested that there are limits to learning-by-doing in financial markets that owe their origins to cognition: how traders select and process information.

In doing so, it was suggested that context matters: knowledge management and learning in the industry is fundamentally shaped by financial risk and uncertainty. At one level, risk and uncertainty are the lifeblood of investment, affecting institutions' and individuals' expectations of the future and their associated investment strategies. Whereas some critics of the financial services industry suggest that it is simply a game played by its participants against the interests of civil society it is shown that, in many respects, knowledge management and learning-by-doing are organised social processes and are often closely scrutinised for their effects on market performance. Indeed, knowledge management and learning-by-doing within and between competing organisations are crucial variables when it comes to framing investment strategies in global financial markets.

Much of the literature in economic geography presupposes that there are significant barriers to knowledge transfer and the application of knowledge produced in one place to similar activities in another place - the implication being that the effectiveness of learningby-doing is mediated by geography-specific institutional formations and social relationships (Faulconbridge 2006). Whereas it was argued that the existence of market risk and uncertainty in global financial markets has resulted in the dominance of one particular model of knowledge management, I also suggested that the investment management industry is forever seeking alternative organisational formations that can withstand the tyranny of the default position. Citing recent research on this issue, it is noted that some organisational models have a distinctive geographical form relying upon the spatialtemporal embeddedness of information and knowledge (market expectations).

Three implications can be drawn from this discussion that could be the basis of a broader research agenda. One important implication has to do with the stability or otherwise of 
knowledge both with respect to its use in different market domains but also the degree to which it can be replicated with benefit over space and time. Perhaps the finance industry is different from other industries in this respect. Nonetheless, one lesson from this discussion is that what counts as knowledge can be highly contingent and subject to unexpected failure with heavy costs for those unable to effectively adapt.

A second implication has to do with how individuals frame expectations of market movements with respect to other similarly placed and/or competing individuals and organisations. At the limit, framing, reframing, and yet reframing again expectations in anticipation of others is self-defeating. It can also be quite costly in terms of the transaction costs of trading, and it can be expensive in terms of lost opportunities if market agents are paralysed by chasing shadows. Furthermore, to the extent to which some markets are more efficient than others in stabilising expectations then those markets will attract more activity than others up until the point where stability dampens investment returns (one explanation of the dominance of global financial markets over local markets and especially emerging markets).

A third implication from the discussion has to do with the relationship between market agents and organisations and whether context-dependent, and cognitive shortfalls in, agent reasoning can be effectively managed by organisational innovation. The coexistence of different types of investment organisations designed to deal with much the same challenges suggests that the ever-present conditions of market risk and uncertainty provide both opportunities for institutional innovation as well as a rationale for the persistence of organisational differences up until the point certain types of organisations fail. This was, quite obviously, a key issue through the 2007 global financial crisis. However, it should also be acknowledged that organisational design is also affected by country-specific regulation, especially as regards the permitted scope of agent activity and the role that their employers play in terms of oversight and management. This issue is now more significant than ever, notwithstanding nearly 40 years of market deregulation. 
These three issues - knowledge contingency, agent expectations, and organisational stability - could be thought specific to financial markets global and local. But they could also be the basis of a shared research program between economic geographers working on different domains of the knowledge economy.

\section{Bibliography}

Agrawal, A., Cockburn, I. and McHal, J. 2006. Gone but not forgotten. Knowledge flows, labor mobility, and enduring social relationships. Journal of Economic Geography 6(5):571591.

Akerlof, G.A. and Shiller, R.J. 2010. Animal Spirits: How Human Psychology Drives the Economy, and Why it Matters for Global Capitalism. Princeton: Princeton University Press.

Amin, A. and Cohendet, P. 2004. Architectures of Knowledge: Firms, Capabilities, and Communities. Oxford: Oxford University Press.

Aragones, E., Gilboa, I., Postlewaite, A. and Schmeidler, D. 2005. Fact-free learning. American Economic Review 95(5):1355-1368.

Arjaliès, D-L., Grant, P., Hardie, I., MacKenzie, D. and Svetlova, E. 2017. Chains of Finance: How Investment Management Is Shaped. Oxford: Oxford University Press.

Arrow, K.J. 1962. The economic implications of learning-by-doing. Review of Economic Studies 29 (3):155-173.

Arrow, K.J. 2014. Commentary. In Speculation, Trading, and Bubbles by Scheinkman, J.A. New York: Columbia University Press, 81-88.

Arrow, K.J. 2016. Commentary. In Creating a Learning Society: A New Approach to Growth, Development, and Social Progress by Stiglitz, J.E. and Greenwald, B.C. New York: Columbia University Press, 504-508.

Baldwin, R. 2016. The Great Convergence: Information Technology and the New Globalisation. Cambridge MA: Harvard University Press.

Bathelt, H. and Cohendet, P. 2014. The creation of knowledge. Local building, global accessing and economic development? Toward an agenda. Journal of Economic Geography 14(5):869-882.

Bathelt, H. and Glückler, J. 2011. The Relational Economy: Geographies of Knowing and Learning. Oxford: Oxford University Press. 
Bathelt, H. and Glückler, J. 2014. Institutional change in economic geography. Progress in Human Geography 38(3):340-363.

Ben-David, I., Franzoni, F., Moussawi, R. and Sedunov, J. 2016. The granular nature of large institutional investors. Working Paper 22247. Cambridge MA: National Bureau of Economic Research.

Bordalo, P., Gennaioli, N., and Shleifer, A. 2012. Salience theory of choice under risk. Quarterly Journal of Economics 127(3):1243-1285.

Bradley, D., Gokkaya, S. and Liu, X. 2017. Before an analyst becomes an analyst: does industry experience matter? Journal of Finance 72(2):751-775.

Breschi, S. and Lissoni, F. 2009. Mobility of skilled workers and co-invention networks. An anatomy of localized knowledge flows. Journal of Economic Geography 9(4):439-468.

Broekel, T. and Boschma, R. 2012. Knowledge networks in the Dutch aviation industry. The proximity paradox. Journal of Economic Geography 12(2):409-433.

Clark, G.L. 2011. Myopia and the global financial crisis: context-specific reasoning, market structure, and institutional governance. Dialogues in Human Geography 1(1):4-25.

Clark, G.L. 2014. Information, knowledge, and investing in offshore financial markets. Journal of Sustainable Finance and Investment 4(4):299-320.

Clark, G.L. 2016. The components of talent: Company size and financial centres in the European investment management industry. Regional Studies 50(1):168-181.

Clark, G.L. 2017. Financial intermediation, infrastructure investment and regional growth. Area Development and Policy 2(3):217-236.

Clark, G.L. 2018a. Behaviour in context. In The New Oxford Handbook in Economic Geography. Clark, G.L., Feldman, M.A. Gertler, M.S., and Wójcik, D. (Eds.). Oxford: Oxford University Press, 154-172.

Clark, G.L. 2018b. The culture of finance. In The Routledge Companion to the Geography of International Business. Cook, G., Johns, J., McDonald, F., Beaverstock, J. and Pandit, N. (Eds.). London: Routledge, 543-563.

Clark, G.L. and Monk, A.H.B. 2017. Institutional Investors in Global Markets. Oxford: Oxford University Press.

Clark, G.L. and Wójcik, D. 2007. The Geography of Finance: Corporate Governance in the Global Marketplace. Oxford: Oxford University Press. 
Cohendet, P., Grandadam, D., Simon, L. and Capdevila, I. 2014. Epistemic communities, localization and the dynamics of knowledge creation. Journal of Economic Geography 14(5):929-954.

Dalio, R. 2017. Principles: Life and Work. New York: Simon and Schuster.

Dixon, A.D. and Monk, A.H.B. 2014. Frontier finance. Annals of the Association of American Geographers 104(4):852-868.

Engelen, E., Ertürk, I., Froud, J., Johal, S., Leaver, A., Moran, M., Nilsson, A. and Williams, K. 2011. After the Great Complacence: Financial Crisis and the Politics of Reform. Oxford: Oxford University Press.

Faulconbridge, J.R. 2006. Stretching tacit knowledge beyond a local fix? Global spaces of learning in advertising professional service firms. Journal of Economic Geography 6(4):517540.

Feldman, M. P. and Lendel, I. 2010. Under the lens: the geography of optical science as an emerging industry. Economic Geography 86:147-171.

Fiedler, K. and Juslin, P. 2006. Taking the interface between mind and environment seriously. In Information Sampling and Adaptive Cognition. Fiedler, K. and Juslin, P.(Eds). New York: Cambridge University Press, 3-29.

Florida, R. 2002. The economic geography of talent. Annals of the Association of American Geographers 92(4):743-755.

Gabe, T.M. and Abel, J.R. 2012. Specialized knowledge and the geographic concentration of occupations. Journal of Economic Geography 12(2):435-453.

Gertler, M.S. 2001. Best practice? Geography, learning and the institutional limits to strong convergence. Journal of Economic Geography 1(1):5-26.

Gertler, M.S. 2003. Tacit knowledge and the economic geography of context, or the undefinable tacitness of being (there). Journal of Economic Geography 3(1):75-99.

Gigerenzer, G., Todd, P. M. and the ABC Research Group. 1999. Simple Heuristics That Make Us Smart. New York: Oxford University Press.

Gilboa, I., Postlewaite, A., Samuelson, L. and Schmeidler, D. 2014. Economic models as analogies. The Economic Journal 124(578):F513-F533.

Glode, V., Green, R.C. and Lowery, R. 2012. Financial expertise as an arms race. Journal of Finance 67(5):1723-1759.

Grabher, G. and Ibert, O. 2013. Distance as asset? Knowledge collaboration in hybrid virtual communities. Journal of Economic Geography 14 (1):97-123. 
Grossman, S.J. 2014. Commentary. In Speculation, Trading, and Bubbles by Scheinkman, J. A. New York: Columbia University Press, 73-80.

Haldane, A. and May, R. 2011. Systemic risk in banking systems. Nature 469(7330):351-355.

Hayek, F.A. 1945. The use of knowledge in society. American Economic Review 35:519-530.

Henrich, J., Boyd, R., Bowles, S., Camerer, C., Fehr, E., Gintis, H., McElreath, R., Alvard, M., Barr, A., Ensminger, J. and Henrich, N.S. 2005. "Economic man" in cross-cultural perspective: Behavioural experiments in 15 small-scale societies. Behavioural and Brain Sciences. 28(6):795-815.

Hilton, D. 2003. Psychology and the financial markets: Applications to understanding and remedying irrational decision-making. Brocas, I. and Cartillo, J.D. (Eds.). The Psychology of Economic Decisions. Volume 1: Rationality and Well-Being. Cambridge: Cambridge University Press, 273-297.

Ho, T.S. and Lee, S.B. 2004. The Oxford Guide to Financial Modelling: Applications for Capital Markets, Corporate Finance, Risk Management, and Financial Institutions. Oxford: Oxford University Press.

Howells, J. 2012. The geography of knowledge. Never so close but never so far apart. Journal of Economic Geography 12(5):1003-1020.

Ibrahim, S.E., Fallah, M.H. and Reilly, R.R. 2008. Localized sources of knowledge and the effect of knowledge spill-overs: An empirical study of inventors in the telecommunications industry. Journal of Economic Geography 9 (3):405-431.

Johnson-Laird, P.N. 1983. Mental Models: Towards a Cognitive Science of Language, Inference, and Consciousness. Cambridge MA: Harvard University Press.

Kahneman, D. 2011. Thinking, Fast and Slow. London: Penguin.

Kahneman, D. and Tversky, A. 1979. Prospect theory: An analysis of decision under risk. Econometrica 47(2):263-292.

Lear, J. 1986. Transcendental anthropology. In Subject, Thought, and Context. Pettit, P. and McDowell, J. (Eds.). Oxford: Oxford University Press, 267-298.

Levinthal, D.A. and March, J.G., 1993. The myopia of learning. Strategic Management Journal 14(S2):95-112.

Lewis, M. 1989. Liar's Poker. New York: W.W. Norton.

Lo, A.W. 2012. Adaptive markets and the new world order. Financial Analysts Journal 68(2): 18-29. 
MacKenzie, D. 2006. An Engine, Not a Camera: How Financial Models Shape Markets. Cambridge MA: MIT Press.

March, J. G. 1994. A Primer on Decision Making. New York: Free Press.

March, J.G., Sproull, L.S. and Tamuz, M. 1991. Learning from samples of one or fewer. Organization Science 2(1):1-13.

Maskell, P. 2014. Accessing remote knowledge--the roles of trade fairs, pipelines, crowdsourcing and listening posts. Journal of Economic Geography 14 (5):883-902.

Maskell, P. and Malmberg, A. 2007. Myopia, knowledge development and cluster evolution. Journal of Economic Geography 7(5):603-618.

Mayer, C. and Vives, X. Eds. 1995. Capital Markets and Financial Intermediation. Cambridge: Cambridge University Press.

Mercier, H. and Sperber, D. 2017. The Enigma of Reason: A New Theory of Human Understanding. London: Penguin Random House.

Monk, A.H.B., Sharma, R. and Sinclair, D.L. 2017. Reframing Finance: New Models of LongTerm Investment Management. Stanford: Stanford University Press.

Pearl, J. 200. Causality. Cambridge: Cambridge University Press.

Pinch, S., Henry, N., Jenkins, M. and Tallman, S. 2003. From 'industrial districts' to 'knowledge clusters': A model of knowledge dissemination and competitive advantage in industrial agglomerations. Journal of Economic Geography 3(4):373-388.

Poon, J.P.H., Pollard, J., Chow, Y.W. and Ewers, M. 2017. The rise of Kuala Lumpur as an Islamic finance frontier. Regional Studies 51(10):1443-1453.

Prendergast, C. 2002. The tenuous trade-off between risk and incentives. Journal of Political Economy 110:1071-1102.

Prendergast, C. 2015. The economics of wild goose chases. Rand Journal of Economics 46:146-164.

Qian, H. 2017. Skills and knowledge-based entrepreneurship: evidence from US cities. Regional Studies 51(10):1469-1482.

Qian, H., Acs, Z.J. and Stough, R.R. 2012. Regional systems of entrepreneurship. The nexus of human capital, knowledge and new firm formation. Journal of Economic Geography 13(4):559-587. 
Riles, A. 2011. Collateral Knowledge: Legal Reasoning in the Global Financial Markets. Chicago: University of Chicago Press.

Rosen, S. 1981. The economics of superstars. American Economic Review 71(5):845-858.

Rosen, S. 1986. Prizes and incentives in elimination tournaments. American Economic Review 76:921-939.

Scheinkman, J.A. 2014. Speculation, Trading, and Bubbles. New York: Columbia University Press.

Shiller, R.J. 2015. Irrational Exuberance (3rd Edn.). Princeton NJ: Princeton University Press.

Shleifer, A. 1985. A theory of yardstick competition. RAND Journal of Economics 16:319-327.

Shleifer, A. 2000. Inefficient Markets: An Introduction to Behavioural Finance. Oxford: Oxford University Press.

Simon, H. A. 1956. Rational choice and the structure of the environment. Psychological Review 63(2):129-38.

Smith, S.J. 2013. Crisis and innovation in the housing economy: a tale of three markets. In Financial Innovation: Too Much or Too Little? Haliassos. M (Ed.). Cambridge MA: MIT Press, 71-102.

van Staveren, I. 2014. The Lehman sisters hypothesis. Cambridge Journal of Economics 38:995-1014.

Stellinga, B.J.P. and Mügge, D.K. 2017. The regulator's conundrum. How market reflexivity limits fundamental financial reform. Review of International Political Economy 24(3):393423.

Stiglitz, J.E. and Greenwald, B.C. 2014. Creating a Learning Society: A New Approach to Growth, Development, and Social Progress. New York: Columbia University Press.

Streeck, W. and Thelen, K. 2005. Introduction. In Beyond Continuity: Institutional Change in Advanced Political Economies. Oxford: Oxford University Press, 1-39.

Thaler R.H. and Sunstein C.R. 2009. Nudge: Improving Decisions About Health, Wealth, and Happiness. London: Penguin.

Urban, M. 2017. Frontier finance and the performance of pension funds. DPhil Thesis. Oxford: School of Geography and the Environment, Oxford University.

Wagner, R. K. 2002. Smart people doing dumb things: the case of managerial incompetence. In Why Smart People Can Be So Stupid. Sternberg, R.J. (Ed). New Haven: Yale University Press, 42-63. 
Weitzman, M. 2007. Subjective expectations and asset-return puzzles. American Economic Review 97(4):1102-1130.

Wójcik, D. 2011. The Global Stock Market: Issuers, investors, and intermediaries in an Uneven World. Oxford: Oxford University Press.

Wójcik, D. 2013. Where governance fails: advanced business services and the offshore world. Progress in Human Geography 37(3):330-347. 
Figure 1. Knowledge Worlds.

\begin{tabular}{|c|c|c|c|}
\hline & \multicolumn{2}{|c|}{ Scope } \\
\hline & & Complete & Incomplete \\
\hline \multirow{2}{*}{ 홈 } & $\begin{array}{l}\overline{\widetilde{\sigma}} \\
\text { हैㅇ } \\
\end{array}$ & $A$ & B \\
\hline & 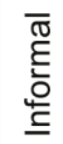 & C & D \\
\hline
\end{tabular}

Source: Author 